\title{
Phylogenetic position of the yeast-like symbiotes of Tagosodes orizicolus (Homoptera: Delphacidae) based on 18S ribosomal DNA partial sequences
}

\author{
Ana M. Xet-Mull ${ }^{1}$, Tania Quesada ${ }^{1}$ \& Ana M. Espinoza ${ }^{1,2}$ \\ 1 Centro de Investigación en Biología Celular y Molecular, Ciudad de la Investigación, Universidad de Costa Rica, San \\ José, Costa Rica. Fax: (506) 207-3190 \\ 2 Escuela de Agronomía, Facultad de Ciencias Agroalimentarias, Universidad de Costa Rica, San José, Costa Rica; \\ amespino@racsa.co.cr
}

Received 16-I-2003. Corrected 18-VIII-2004. Accepted 25-VIII-2004.

\begin{abstract}
Tagosodes orizicolus Muir (Homoptera: Delphacidae), the endemic delphacid species of tropical America carries yeast-like symbiotes (YLS) in the abdominal fat bodies and the ovarial tissues, like other rice planthoppers of Asia. These YLS are obligate symbiotes, which are transmitted transovarially, and maintain a mutualistic relationship with the insect host. This characteristic has made in vitro culture and classification of YLS rather difficult using conventional methods. Nevertheless, microorganisms of similar characteristics have been successfully classified by using molecular taxonomy. In the present work, the YLS of Tagosodes orizicolus (YLSTo) were purified on Percoll@ gradients, and specific segments of 18S rDNA were amplified by PCR, cloned and sequenced. Sequences were aligned by means of the CLUSTAL V (DNASTAR) program; phylogenetic trees were constructed with the Phylogeny Inference Package (PHYLIP), showing that YLSTo belong to the fungi class Pyrenomycetes, phylum Ascomycota. Similarities between $98 \%$ and $100 \%$ were observed among YLS of the rice delphacids Tagosodes orizicolus, Nilaparvata lugens, Laodelphax striatellus and Sogatella furcifera, and between $89.8 \%$ and $90.8 \%$ when comparing the above to YLS of the aphid Hamiltonaphis styraci. These comparisons revealed that delphacid YLS are a highly conserved monophyletic group within the Pyrenomycetes and are closely related to Hypomyces chrysospermus. Rev. Biol. Trop. 52(3): 777-785. Epub 2004 Dic 15.
\end{abstract}

Key words: Tagosodes orizicolus, yeast-like symbiotes, $18 \mathrm{~S}$ rDNA, genetic relationships, Pyrenomycetes, rice planthoppers.

Palabras clave: Tagosodes orizicolus, simbiontes semejantes a levaduras, DNAr 18S, relación genética, Pyrenomycetes, saltahojas del arroz.

Tagosodes orizicolus (Homoptera: Delphacidae) is one of the most important insects affecting rice (Oryza sativa) in tropical America (McGuire et al. 1960, Trujillo 1968). It is a rice feeder, which is also the vector for the rice hoja blanca virus (RHBV) (McGuire et al. 1960, Gálvez 1968, 1969, Everett 1969, Nault 1994). T. orizicolus is also known to complete its life cycle on Oryza glumaepatula, a wild rice species endemic to tropical America that belongs to the same genome type as $O$. sativa (A. Espinoza, unpublished results). This species is endemic and restricted to tropical America, unlike the rice delphacids Laodelphax striatellus, Sogatella furcifera and Nilaparvata lugens that are distributed throughout Asia.

Delphacids and other insect species show a close relationship with intracellular and extracellular symbiotic microorganisms of possible prokaryotic and eukaryotic origin (Buchner 1965, Chen et al. 1981a). Studies held on fifty species of delphacids revealed that 37 percent of the microorganisms on these insects are yeast-like symbiotes (YLS) (Müller 1962). Intracellular symbiotes of the 
Homoptera have also been studied through histology, production of aposymbiotic insects, transovarial infection and the effect on insect nutrition (Noda 1974, Noda and Saito 1979a and 1979b, Kusumi et al. 1979 and 1980, Houck 1980, Chen et al. 1981a,b, Nasu 1981, Frölich 1989 and Sasaki et al. 1996). Delphacids have microbial symbiotes in their bodies, probably contributing to the lack of proteinases in their salivary glands, like aphids and other insects that are phloem feeders (Frölich 1989). It has been observed that a decrease in the YLS populations in the insect produces deleterious effects, such as reduction in nymph emergence, ecdisis inhibition, decrease in insect size and reproductive failure (Chen et al. 1981b, Fredenhagen et al. 1987 and Frölich 1989). It is also known that the main source of esterol (24-methylenecholesterol) is provided by the YLS, since the lack of these symbiotes affects the insect esterol metabolism, a precursor of ecdisone (Noda and Saito 1979b, Fredenhagen et al. 1987, Frölich 1989).

YLS are transmitted vertically by an intra-ovarian process, and later infect the fat tissues of the insect's abdomen (Mitsuhashi 1975, Kusumi et al. 1979, Chen et al. 1981a, Fröhlich 1989), as it occurs with the delphacids Laodelphax striatellus and Nilaparvata lugens. In the case of Tagosodes orizicolus, YLS inhabit the intracellular spaces in the fat bodies of the insect's abdomen, in diffuse patterns associated with syncitia, but without forming mycetomes (Espinoza et al. 2004).

Purification and isolation of YLS have been performed on eggs and adult delphacids; however, maintenance of cultures has not been successful because these microorganisms undergo autocatalytic processes (Mitsuhashi 1975, Kusumi et al. 1979, Nasu et al. 1981, Chen et al. 1981a). This situation has limited the application of conventional classification and identification methods that require in vitro culture of the YLS.

An alternative method for the classification of these YLSs was developed by Noda $e t$ al. (1995), based on the partial 18S rDNA sequences. They determined the phylogenetic relationships of the YLS of three rice delphacids: Nilaparvata lugens (YLSNl), Sogatella furcifera (YLSSf) and Laodelphax striatellus (YLSLs). These were classified among the Pyrenomycetes in the subphylum Ascomycota. These symbiotes had a monophyletic origin and close genetic distances. Aphids also have symbiotic microorganisms; however, these are mainly prokaryotes. One exception is found in the aphid Hamiltonaphis styraci, which, like delphacids, contains YLS belonging to the Pyrenomycetes class (Buchner 1965, Houk and Griffiths 1980, Fukatsu and Ishikawa 1992, 1996, Fukatsu 1994, Fukatsu and Ishikawa 1996). The beetles Stegobium paniceum and Lasioderma serricorne also have yeast-like symbiotes. These microorganisms are transmitted from generation to generation when the newly emerged larvae feed on the yeast-covered eggshell. These symbiotes form a monophyletic group in the Discomycetes class (Noda and Kodama 1996).

The purpose of this research is to determine the phylogenetic relationships of the yeast-like symbiotes of the delphacid Tagosodes orizicolus with other ascomycetes fungi, as well as to determine the nucleotide similarity of the YLS of T. orizicolus with the YLSs of Nilaparvata lugens, Sogatella furcifera, Laodelphax striatellus and Hamiltonaphis styraci, using partial sequences of the $18 \mathrm{~S}$ rDNA.

\section{MATERIALS AND METHODS}

Sample collection: Tagosodes orizicolus was collected from sixty day-old-plants in rice fields in the Costa Rican rice growing regions of Guanacaste (N 10²9'04.9” ; W 085 24'23.7') and Parrita (N 09³4'15.3”'; W 084'33'23.3"). Capture was performed with a $32 \mathrm{cc}$ motor pump (Craftzman, model 358797920), modified by placing a mesh in the suction duct. Insects were transported on ice and stored at $-20^{\circ} \mathrm{C}$. Adult selection was performed according to male and female genitalia (Mora et al. 2002). 
Purification of yeast-like symbiotes: Purification was performed on Percoll@ gradients, based on the protocol described by Noda and Omura (1992). One gram of adult insects was homogenized on a porcelain mortar with 10 volumes of $0.85 \% \mathrm{NaCl}$. Each sample was filtered on cotton cloth and centrifuged for 5 min at $3500 \mathrm{rpm}$ on a clinic IEC centrifuge. The pellet was washed twice, re-suspended in $0.85 \% \mathrm{NaCl}$ and mixed with four volumes of Percoll (Pharmacia LKB, Sweden). The mixture was centrifuged at $26000 \mathrm{rpm}$ for forty minutes in a Beckman, SW50.1 rotor and a second gradient was performed to remove tissue debris. A standard was prepared by placing 51 of each of the floating density markers resuspended in $1 \mathrm{ml} 0.85 \% \mathrm{NaCl}$ and adding 4 volumes of Percoll. The standard was centrifuged under the same conditions as the samples. Each fraction of the gradient was observed under a light microscope (10X and 40X), confirming the presence of YLS.

DNA extraction: Yeast DNA was extracted by modifying the methods described by Cenis (1992) and Noda et al. (1995). YLSTo were re-suspended in $50 \mathrm{mM}$ EDTA, $\mathrm{pH} 8,1 / 3$ volume of $1 \%$ liticase (Sigma) on $0.01 \mathrm{M}$ sodium phosphate $\mathrm{pH} 7.5$ and $50 \%$ glycerol. Spheroplasts were obtained by incubation at $37^{\circ} \mathrm{C}$ during 45-60 minutes, followed by centrifugation. The pellet was homogenized in 3001 buffer (200 mM Tris.HCl, pH 8.5, 250 $\mathrm{mM} \mathrm{NaCl}, 25 \mathrm{mM}$ EDTA, $0.5 \%$ SDS and glass beads of 212-300 microns). Samples were then treated with $150 \quad 1$ of $3 \mathrm{M}$ sodium acetate and incubated at $-30^{\circ} \mathrm{C}$ for one hour, followed by centrifugation at $13000 \mathrm{rpm}$ for ten minutes. The supernatant was recovered and DNA was obtained by precipitation with isopropanol. It was then re-suspended in distilled water and quantified by UV spectrophotometry at $260 \mathrm{~nm}$.

PCR amplification: Partial sequences of 18S rDNA were amplified from total DNA. The PCR protocol and the primers used were those described by Noda and collaborators (1995). Approximately $40 \mathrm{ng}$ of DNA were used for each reaction and amplification products were analyzed in $0.7 \%$ agarose gels. The bands obtained were cut and the products were extracted according to the QIAquick gel extraction protocol (QIAGEN 1997). Ligation and transformation were performed according to the pGEM-T Vector System I (Promega 1997) protocol. The samples were incubated on Luria Bertani (LB) broth for four hours with agitation, and the DNA preparation for sequencing was made by following the protocol of Sambrook et al. (1989). The clones were stored in $30 \%$ glycerol at $-70^{\circ} \mathrm{C}$.

DNA sequencing: DNA was sequenced according to the enzymatic method described by Sanger and collaborators (1977), using the ABI PRISM automatic sequencing system. Sequences were aligned with those of different fungi and yeasts, as well as with other YLSs from rice delphacids, aphids and coleopterans. The sequence search was performed on the European Molecular Biology (EMBL) and GenBank databases using the programs for the FASTA family. The yeasts and fungi selected for the phylogenetic analyses are shown in Table 1, along with their respective access numbers. Sequences were aligned with the CLUSTAL V Multiple Sequence Alignment Program distributed by D.G. Higgins (EMBL) and the Phylogeny Inference Package (PHYLIP) version 3.5C (Felsenstein 1993). Re-sampling analyses were performed with 1000 bootstrapping events and phylogenetic trees were constructed with the Neighbor-joining procedure.

\section{RESULTS}

The symbiotes were located in densities between $1.087 \mathrm{~g} / \mathrm{ml}$ to $1.119 \mathrm{~g} / \mathrm{ml}$ on Percoll gradients, densities similar to those previously reported for the YLS of other delphacids. The YLSTo were thus exhaustively purified for DNA extraction in order to avoid contamination by host DNA. The sequence of the dominant species of YLSTo was obtained through this procedure, because T. orizicolus, as well as other delphacids, could host other species of symbiotes among their microbiota. 
TABLE 1

List of fungi* and yeast-like symbiotes $(Y L S)^{+}$from which the $18 S$ rDNA sequences were used for phylogenetic analysis and their respective accession numbers in the databases

Fungi and Symbiotes

Subphylum Ascomycotina

Plectomycetes

Arcoesphaera apis

Aspergillus fumigatus

Coccidioides immitis

Pyrenomycetes

Hypomyces chrysospermus

Ophiostoma ulmi

Podospora anserina

Glomerella cingulata ${ }^{\circ}$

Microascus cirrosus

Chaetomium elatum

Leucostoma persoonii

Ophiostoma schenckii

Sordaria fimicola

YLS of Nilaparvata lugens

YLS of Sogatella furcifera

YLS of Laodelphax striatellus

YLS of Hamiltonaphis styraci

Discomycetes

Lecanora dispersa

Spathularia flavida

Sphaenophorus globosus

YLS of Lasioderma serricone

Hemiascomycetes

Candida albicans

Saccharomyces cerevisiae

Basidiomycetes

Ustilago maydis
Access No.

M 83264

M55626

M55627

M89992

M83261

X54864

M55640

M89994

M83257

M83259

M85053

X69851

D38474

D38476

D38478

D55719

L37535

Z30239

L37532

D49656

X53497

J01353

X62396

* Noda and Kodama (1996), GenBank and EMBL. ${ }^{+}$Noda et al. (1995), Noda and Kodama (1996), Fukatsu and Ishikawa (1996). ${ }^{\circ}$ Registered by the name of Colletotrichum gloeosporioides.

Table 2 shows the partial sequences of the $18 \mathrm{~S}$ rDNA of YLS Tagosodes orizicolus, as compared to the NS1-2 region, positions 46 to 531 of Saccharomyces cerevisiae 18S rDNA. The analysis also included sequences from YLS of the delphacids Nilaparvata lugens, Laodelphax striatellus and Sogatella furcifera.

Upon comparing the YLS sequences of $T$. orizicolus with those of the YLS from $N$. lugens, S. furcifera and $L$. striatellus, ten variable positions among the delphacid symbiotes were found (Table 2). Six additional variable positions were obtained when the YLSs of the aphid $H$. styraci were included (data not shown). As observed, YLSSf and YLSLs showed the same nucleotide changes along the whole region analyzed in relation to YLSNl. In the mean time, YLSTo varied in the positions 389,423 and 437 in relation to the former three. The most variable sequence among the symbiotes of rice delphacids was that of YLSNl.

Diversity in the previously described positions was also analyzed by similarity percentages among the sequences (Table 3 ).

In this sense, YLSTo are more similar to other delphacid YLSs, such as YLSLs and YLSSf, showing $99.4 \%$ similarity, while the 
TABLE 2

Nucleotide changes in positions 46 to 531 of the NS1-2 region of the 18S rDNA of yeast-like symbiotes of four rice delphacid species

Yeast-like symbiotes

YLS of Nilaparvata Lugens YLS of Sogatella furcifera YLS of Laodelphax striatellus YLS of Tagosodes orizicolus

$\begin{array}{cccccccccc}72 * & 222 & 234 & 236 & 272 & 389 & 423 & 437 & 522 & 523 \\ & & & & & & & & & \\ \text { A } & \text { A } & \text { T } & \text { G } & \text { T } & \text { G } & \text { G } & \text { A } & \text { T } & \text { C } \\ - & - & \text { C } & - & \text { C } & \text { G } & \text { G } & \text { A } & \text { C } & \text { T } \\ - & - & \text { C } & - & \text { C } & \text { G } & \text { G } & \text { A } & \text { C } & \text { T } \\ - & - & \text { C } & - & \text { C } & \text { A } & - & \text { G } & \text { C } & \text { T }\end{array}$

* Positions referred to the sequence of $S$. cerevisiae. The sign (-) means nucleotide absence. Gaps were considered as a fifth state.

TABLE 3

Similarity and divergence percentages among 18S rDNA partial sequences (positions 46-531) of Nilaparvata lugens, Sogatella furcifera, Laodelphax striatellus, Tagosodes orizicolus and Hamiltonaphis styraci yeast-like symbiotes *

\begin{tabular}{lccccc} 
& \multicolumn{5}{c}{ \% Similarity } \\
& YLSNl & YLSSf & YLSLs & YLSTo & YLSHs \\
YLSNl & & & & & \\
YLSSf & 0.8 & & 100.0 & 99.4 & 90.8 \\
YLSLs & 0.8 & 0.0 & & 99.4 & 90.8 \\
YLSTo & 1.2 & 0.4 & 0.4 & & 90.2 \\
YLSHs & 1.6 & 1.1 & 1.1 & 1.6 & \\
& & & & &
\end{tabular}

\footnotetext{
* Data obtained by the Clustal V multiple sequence alignment method.
}

similarity with YLSNl was of $98 \%$. In addition, YLSTo exhibits a $90.2 \%$ similarity with those from the YLS of the aphid Hamiltonaphis styraci. In other words, the YLSTo have diverged less in relation to YLSLs and YLSSf $(0.4 \%)$, at an intermediate level as compared to YLSNl (1.2\%) and to a higher degree with respect to YLSHs (1.6\%) (Table 3).

The position of YLSTo within the phylum Ascomycota was determined after aligning the complete sequence of the NS1-6 (1438 nt) clone with that of eleven ascomycete fungi: Arcoesphaera apis, Aspergyillus fumigatus, Coccidioides immitis (Class Plectomycetes); Hypomyces chrysospermus, Ophiostoma ulmi, Podospora anserina (Class Pyrenomycetes); Lecanora dispersa, Spathularia flavida, Spaenophorus globosus (Class Discomycetes);
Candida albicans, Saccharomyces cerevisiae (Order Saccharomycetales) and Ustilago maydis (Class Basidiomycetes) as an outgroup (Fig. 1). The analyses revealed that YLSTo grouped with H. chrysospermus, O. ulmi and P. anserina in the class Pyrenomycetes. Furthermore, the conformation of three other subgroups was observed. According to the classic taxonomic division (morphologic characteristics), these three subgroups correspond to the fungi Discomycetes, Plectomycetes and Saccharomycetales of the phylum Ascomycota (Fig. 1).

The relationship between YLSTo with the Pyrenomycetes was determined by comparing the symbiote $1386 \mathrm{nt} 18 \mathrm{~S}$ rDNA segment with that from nine fungi of this class: $H$. chrysospermus, $O$. ulmi, $P$. anserina, Glomerella cingulata, Microsacus cirrosus, 


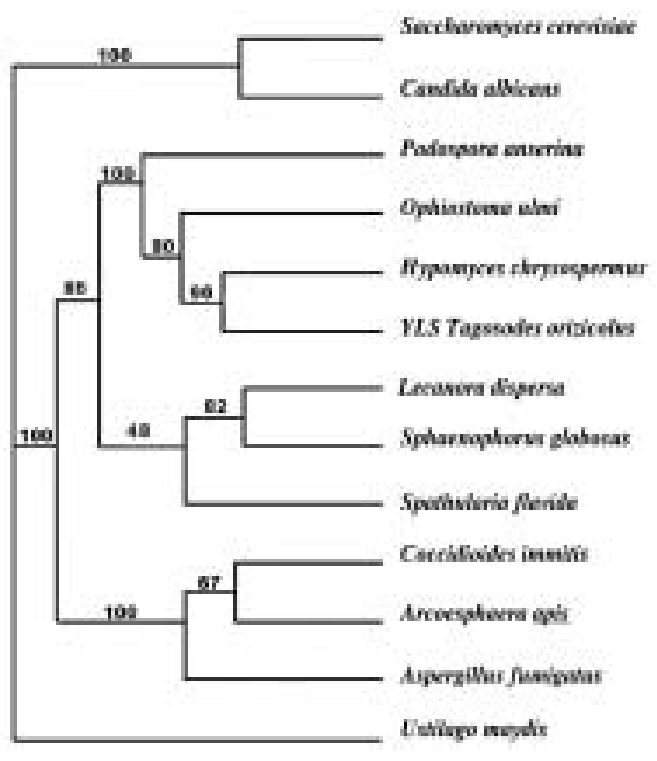

Fig. 1. Phylogenetic relationships of Tagosodes orizicolus yeast-like symbiotes and eleven species of yeast and fungi of the phylum Ascomycota, based on the NS1-6 (1438 nt) $18 \mathrm{~S}$ rDNA nucleotide partial sequences. The tree was constructed with the Neighbor-joining procedure from the Phylogeny Inference Package (PHYLIP) (Felsenstein 1993). Numbers correspond to the re-sampling percentage after 1000 random bootstrapping events.

Chaetomium elatum, Leucostoma persoonii, Ophiostoma schenckii and Sordaria fimicola. They conformed a monophyletic group along with $H$. Chrysospermus, G. cingulata and $M$. cirrosus. S. flavida (Discomycete) was included as an external group (Fig. 2).

The analysis of the $18 \mathrm{~S}$ rDNA partial sequences (1 a $531 \mathrm{nt}$ ) revealed very close relationships among the YLSTo and other delphacid and aphid YLS (Fig. 3). The dendrogram showed a monophyletic origin of the delphacid YLS and very short genetic distances between YLSTo and YLSLs, YLSSf and YLSNl, but slightly larger distances with YLSHs. The symbiotes of the beetle Lasioderma serricorne (YLSLse) were placed outside the class Pyrenomycetes and grouped with S. flavida, both Discomycetes.

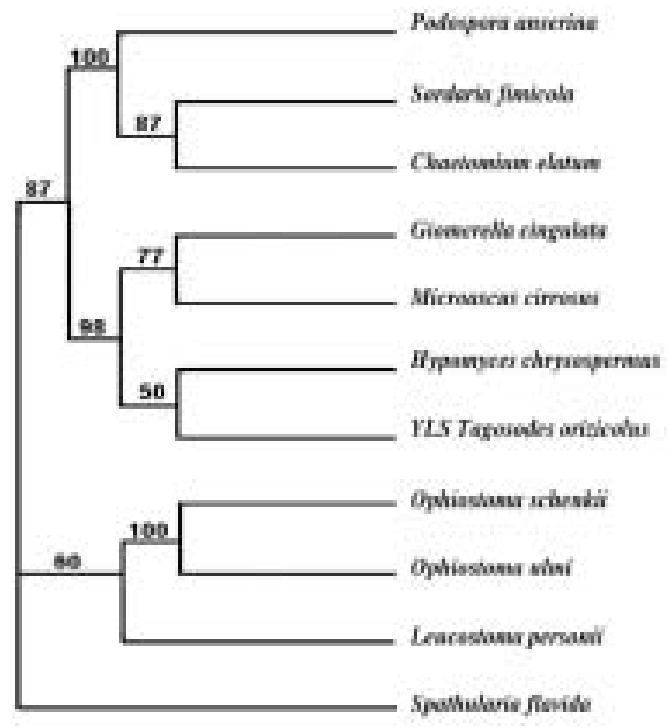

Fig. 2. Phylogenetic relationships of Tagosodes orizicolus yeast-like symbiotes with the Pyrenomycetes class, based on $18 \mathrm{~S}$ rDNA partial sequence (1386 nt). The tree was constructed according to the Neighbor-joining procedure from the Phylogeny Inference Package (PHYLIP) (Felsenstein 1993). Numbers correspond to the re-sampling percentage after 1000 random bootstrapping events.

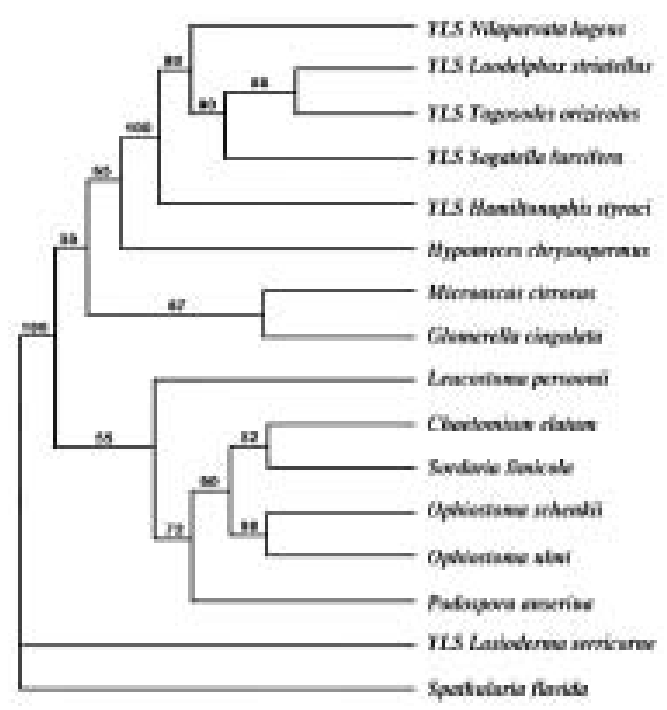

Fig. 3. Phylogenetic relationships of Tagosodes orizicolus and other delphacid and aphid yeast-like symbiotes with several species of Pyrenomycetes and Discomycetes (phylum Ascomycota), based on the NS1-2 (531 nt) 18S rDNA nucleotide partial sequence. The tree was constructed according to the Neighbor-joining procedure from the Phylogeny Inference Package (PHYLIP) (Felsenstein 1993). Numbers correspond to the re-sampling percentage after 1000 random bootstrapping events. 


\section{DISCUSSION}

The yeast-like symbiotes of Tagosodes orizicolus clustered with members of the class Pyrenomycetes when compared to other members of the phylum Ascomycota, like Plectomycetes, Discomycetes, Saccharomycetales and Basidiomycetes (Fig. 1). The clustering of YLSTo, along with G. cingulata, M. cirrosus, and $H$. chrysospermus, within the Pyrenomycetes, supported the above observation (Fig. 2). YLSTo and other delphacid and aphid yeast-like symbiotes formed a separate cluster, when compared to other members of the Pyrenomycetes and Discomycetes (Fig. 3). In contrast, the beetle YLSLs showed affinity to Spathularia flavida, a Discomycetes, suggesting that different insect orders may have been colonized by YLS belonging to different groups within the phylum Ascomycota.

The close similarity (more than 90\%) observed between the delphacid and aphid symbiotes suggests that an ancestral Pyrenomycete may have parasitized a homopteran common ancestor before these two groups diverged. This ancestral Pyrenomycete may have developed a mutualist symbiotic relationship, a role that yeast-like symbiotes presently have. The phylogenetic distribution of the symbiotes in both planthoppers and aphids is complex (bacterioid and yeast-like type), which may indicate that some events, such as symbiote acquisition and replacement, could have sprung either from the evolution from a common ancestor or from horizontal transfer (Fukatsu et al. 1994, Moran and Baumann 1994, Fukatsu and Ishikawa 1996).

It is interesting to emphasize the high degree of similarity (over 98\%) observed in the 18S rDNA partial sequences among the YLSs of Asian and American rice delphacids, especially considering that the YLS might have been present in a common ancestor. The high similarity observed might be reasonable, considering the crucial role of the symbiotes in the physiology, development and reproduction of their delphacid hosts, especially since significant genetic variations on the YLS could directly affect the host fitness and reproductive success. In addition, it is important to mention that the $18 \mathrm{~S}$ rDNA partial sequences used in this study are likely to be highly conserved, due to the important role of rDNA in protein synthesis, and that analyzing other sequences in the YLS genome could result in higher levels of diversity.

The phylogenetic relationships of the YLSs of three Asian rice-feeding delphacids (N. lugens, S. furcifera and L striatellus) were previously described by Noda and collaborators (1995), and were compared to twenty species of other Ascomycetes. It was observed that the YLSTo showed high degree of similarity to those of Asian delphacids; although, $T$. orizicolus is strictly confined to tropical America. Therefore, the colonization of a delphacid YLS ancestor may have occurred before these species diverged, possibly before the continental drift. It is important to recall that delphacids maintain very close relationships with their plant hosts. For example, T. orizicolus is only capable of feeding and reproducing on rice (Oryza sativa) and in $O$. glumaepatula (Hernández and Espinoza, unpublished results), an endemic wild Oryza species of tropical America. O. glumaepatula is related to other Asian and African Oryza species of the $O$. sativa complex, sharing the AA type genome (Akimoto 1999). If cultivated rice was introduced to America less than 500 years ago (Cabezas and Espinoza 2001), it is probable that $O$. glumaepatula may have been the original host of T. orizicolus and that, after the introduction of rice in America, this insect may have adapted to the new host.

This first report of yeast-like symbiotes in the American delphacid Tagosodes orizicolus offers interesting results concerning the relationship of this organism as compared to other delphacid YLS, as well as other fungi from the phylum Ascomycota. However, in order to understand the acquisition patterns and the evolutionary origin of yeast-like symbiotes, it is still necessary to perform more detailed molecular phylogenetic studies on the symbiotes as well as on their homopteran hosts. 


\section{ACKNOWLEDGMENTS}

The authors wish to thank David Tobin for his support in performing the statistical analyses, and to Xiaoai Chen, of Yale University, for the sequencing of the $18 \mathrm{~S}$ rDNA clones.

\section{RESUMEN}

Tagosodes orizicolus Muir (Homoptera: Delphacidae) es una especie endémica de América tropical que al igual que otros saltahojas de Asia, tiene simbiontes levaduriformes (YLS, por sus siglas en Inglés) en los cuerpos grasos del abdomen y en los tejidos de los ovarios. Los YLS son simbiontes obligados que se transmiten transovarialmente y que mantienen relaciones mutualística con el insecto hospedero. Esta característica ha hecho muy difícil su cultivo in vitro y por ende su clasificación utilizando métodos convencionales. Sin embargo, otros microorganismos de características similares se han clasificado con éxito utilizando taxonomía molecular. El presente trabajo tiene como objetivo caracterizar los YLS del delfácido Tagosodes orizicolus (YLSTo). Para ello se purificaron los YLSTo en gradientes de Percoll® y el ADN extraído se amplificó por PCR utilizando iniciadores específicos para secuencias parciales del ADN ribosomal 18S. Dichos fragmentos se clonaron y secuenciaron posteriormente. Las secuencias se alinearon mediante el programa CLUSTAL V DNASTAR) y se construyeron árboles filogenéticos con el programa Phylogeny Inference Package (PHYLIP). Se encontró que los YLSTo pertenecen a la clase de hongos Pyrenomycetes, phylum Ascomycota. Se observaron índices de similaridad entre $98 \%$ y $100 \%$ entre los YLS de Tagosodes orizicolus, Nilaparvata lugens, Laodelphax striatellus and Sogatella furcifera (todos delfácidos de arroz), e índices de similaridad entre $89.8 \%$ y $90.8 \%$ al compararse con los YLS del áfido Hamiltonaphis styraci. Estas comparaciones revelaron que los YLS de los delfácidos constituyen un grupo monofilético altamente conservado dentro de los Pyrenomycetes y que se relacionan cercanamente con Hypomyces chrysospermus.

\section{REFERENCES}

Akimoto, M. 1999. Biosystematics of the Oryza AA genome wild taxa (Oryza sativa complex) by morpho-physiological traits, isozyme and RFLPs. Ph.D. Thesis. Hokkaido University, Japan. 53 p.

Buchner, P. 1965. Endosymbiosis of animals with plant microorganisms. Interscience. Nueva York.

Cenis, J.L. 1992. Rapid extraction of fungal DNA for PCR amplification. Nucleic Acids Res. 20(9): 2380.
Chen, D.Q., B.C. Campbell \& A.H. Purcell. 1996. A new rickettsia from an herbivorous insect, the pea aphid Acyrthosiphon pisum (Harris). Curr. Microbiol. 33(2): 123-128.

Chen, C-C., L-L. Chen, C-C. Kuan \& R.F. Hou. 1981a. Studies on the intracellular yeast-like symbiote in the brown planthopper, Nilaparvata lugens Stål. I. Histological observations and population changes of the symbiote. Z. Ang. Ent. 91: 321-327.

Chen, C-C., L-L. Chen \& R.F. Hou. 1981b. Studies on the intracellular yeast-like symbiote in the brown planthopper, Nilaparvata lugens Stål. II. Effects of antibiotics and elevated temperature on the symbiotes and their host. Z. Ang. Ent. 91: 321-327.

Everett, T. 1969. Vectors of hoja blanca virus. In J.H. Press (ed.). The virus disease of the rice plant. Proceedings of the Symposium at the International Rice Research Institute (IRRI). Baltimore, Maryland. $354 \mathrm{p}$.

Espinoza, A.M., A.M. Xet-Mull, R. Mora \& E. Sánchez 2004. Morphologic characterization of yeast-like symbiotes of Tagosodes orizicolus (Homoptera: Delphacidae) by light and electron microscopy. Rev. Biol. Trop. 52: in press.

Felsenstein, J. 1993. PHYLIP (Phylogeny Inference Package) version 3.6. Distributed by the author. Department of Genetics, University of Washington, Seattle.

Fredenhagen, A., P. Kenny, H. Kita, H. Komura, Y. Naya, K. Nakanishi, L. Nishiyama, M. Sugiura \& S. Tamura. 1987. Role of intracellular symbiotes in planthoppers, p. 101-108. In R. Greenhalgh \& T.R. Roberts (eds.). Pesticide Science and Biotechnology. Blackwell, London.

Fröhlich, G. 1989. Endosymbiosis of phloem sap sucking planthoppers with special reference to Sogatodes orizicola (Muir) feeding on Oryza sativa L. Beitr. Ent. 39: S393-412.

Fukatsu, T. 1994. Endosymbiosis of aphids with microorganisms: A model case of dynamic endosymbiotic evolution. Plant Species Biol. 9: 145-154.

Fukatsu, T. \& H. Ishikawa. 1992. A novel eukariotic extracellular symbiont in an aphid, Astegopteryx styraci (Homoptera, Aphididae, Hormaphidinae). J. Insect. Physiol. 38: 765-773.

Fukatsu, T. \& H. Ishikawa. 1996. Phylogenetic position of yeast-like symbiont of Hamiltonaphis styraci (Homoptera, Aphididae) based on 18S rDNA sequence. Insect Biochem. Molec. Biol. 26: 383-388.

Fukatsu, T., S. Aoky, U. Kurosu \& H. Ishikawa. 1994. Phylogeny of Cerataphidini Aphids revealed by their symbiotic microorganisms and basic structure of 
their galls: Implications for host-symbiont coevolution and evolution of sterile soldier castes. Zool. Sci. 11: 613-623.

Gálvez, G.E. 1968. Transmission studies of the hoja blanca virus with highly active, virus-free colonies of Sogatodes oryzicola. Phytopathology 58: 818-821.

Gálvez, G.E. 1969. Transmission of hoja blanca virus of rice. In J.H. Press. The virus disease of the rice plant. Proceedings of the Symposium at the International Rice Research Institute (IRRI). Baltimore, Maryland. 354p.

Houk, E.J. \& G.W. Griffiths. 1980. Intracellular symbiotes of the Homoptera. Ann. Rev. Entomol. 25: 161-187.

Kusumi, T., Y. Suwa, H. Kita \& S. Nasu. 1979. Symbiotes of Planthoppers: I. The isolation of intracellular symbiotes from the smaller brown planthopper, Laodelphax striatellus Fallén (Homoptera: Delphacidae). Appl. Ent. Zool. 14: 459-463.

Kusumi, T., Y. Suwa, H. Kita \& S. Nasu. 1980. Properties of intracellular symbiotes from the smaller brown planthopper, Laodelphax striatellus Fallén (Homoptera: Delphacidae). Appl. Ent. Zool. 15: 129-134.

McGuire, J.U., W.W. McMillian \& H.A. Lamey. 1960. Hoja blanca disease of rice and its insect vector. Rice J. 63: $15-28$.

Mitsuhashi, J. 1975. Cultivation of intracellular yeast-like organisms in the Smaller Brown Planthopper, Laodelphax striatellus Fallén (Homoptera: Delphacidae). Appl. Ent. Zool. 10: 243-245.

Mora, R., A. Retana \& A.M. Espinoza. 2001. External morphology of Tagosodes orizicolus Muir (Homoptera: Delphacidae) revealed by scanning electron microscopy. Ann. Enthomol. Soc. Amer. 94(3): 438:448.

Moran, N. \& P. Baumann. 1994. Phylogenetics of cytoplasmically inherited microorganisms of arthropods. Trends Ecol. Evol. 9: 15-20.

Müller, H.J. 1962. Neuere Vostellunge über Verbreitun und Phylogenie des Endosymbiose der Qikade. Z. Morph. Ökol. Tiere. 51: S190-210.

Nasu, S., T. Kusumi, Y. Suwa \& H. Kita. 1981. Symbiotes of planthoppers: II. Isolation of intracellular symbiotic microorganisms from the brown planthopper, Nilaparvata lugens Stål. and immunological comparison of the symbiotes associated with rice planthoppers (Homoptera: Delphacidae). Appl. Ent. Zool. 16: 88-93.

Nault, L.R. 1994. Transmission biology, vector specificity and evolution of planthopper-transmitted viruses, $\mathrm{p}$.
429-448. In R.F. Denno \& T.J. Perfect (eds). Planthoppers: Their ecology and management. Chapman \& Hall, London.

Noda, H. 1974. Preliminary histological observation and population dynamics of intracellular yeast-like sumbiotes in the smaller brown planthopper, Laodelphax striatellus (Homoptera: Delphacidae). Appl. Ent. Zool. 9: 275-277.

Noda, H. \& K. Kodama. 1996. Phylogenetic position of yeast-like endosymbionts of anobiid beetles. Appl. Environ. Microbiol. 62: 162-167.

Noda, H. \& T. Omura. 1992. Purification of yeast-like symbiotes of planthoppers. J. Invert. Pathol. 59: 104-105.

Noda, H. \& T. Saito. 1979a. Effects of high temperature on the development of Laodelphax striatellus Fallén (Homoptera: Delphacidae). Appl. Ent. Zool. 14: 64-75.

Noda, H. \& T. Saito. 1979b. The role of intracellular yeastlike symbiotes in the development of Laodelphax striatellus Fallén (Homoptera: Delphacidae). Appl. Ent. Zool. 14: 453-458.

Noda, H., N. Nakashima \& M. Koizumi. 1995. Phylogenetic position of yeast-like symbiotes of rice planthoppers based on partial 18S rDNA sequences. Insect Biochem. Molec. Biol. 25: 639-646.

Promega. 1997. Technical manual of pGEM-T and pGEM-T Easy Vector Systems. Promega Corp, Wisconsin, $26 \mathrm{p}$.

QIAGEN. 1997. QIAquick gel extraction kit protocol, p. 24-25. In Anonymous (ed.). QIAquick Spin Handbook. QIAGEN, California.

Sambrook, J., E.F. Fritsch \& T. Maniatis. 1989a. Molecular cloning. A laboratory manual. CSH, New York. p. 1.29-1.30.

Sanger, F., G.G. Brownlee \& B.G. Barrell. 1977. DNA sequencing with chain-terminating inhibitors. Proc. Natl. Acad. Sci. 74: 5463.

Sasaki, T., M. Kawamura \& H. Ishikawa. 1996. Nitrogen recycling in the brown planthopper, Nilaparvata lugens: involvement of yeast-like symbionts in uric acid metabolism. J. Insect. Physiol. 42: 125-129.

Trujillo, G. 1968. Relación entre la aplicación de insecticidas and la transmisión de la hoja blanca del arroz por Sogata orizicola. Agron. Trop. 18: 441-447.

Zamora, A. 2001. Diversidad morfológica y genética de las especies de Oryza (Poaceae) nativas de Costa Rica. M.Sc. Thesis. Universidad de Costa Rica, Costa Rica. 178 p. 